\title{
Why biodiversity is important to oceanography: potential roles of genetic, species, and trophic diversity in pelagic ecosystem processes
}

\author{
J. Emmett Duffy ${ }^{1, *}$, John J. Stachowicz ${ }^{2}$ \\ ${ }^{1}$ School of Marine Science and Virginia Institute of Marine Science, The College of William and Mary, 1208 Greate Road, \\ Gloucester Point, Virginia 23062-1346, USA \\ ${ }^{2}$ Section of Evolution and Ecology, University of California, Davis, California 95616, USA
}

\begin{abstract}
The functioning of the global ecosystem is mediated in large part by pelagic marine organisms through their influence on biomass production, elemental cycling, and atmospheric composition. Growing theoretical and empirical evidence suggests that the stability and functioning of this complex system may depend, not only on aggregate biomass and production of pelagic producers and consumers, but also on the composition and richness of taxa within those compartments. Yet rigorous experimental tests of relationships between diversity and these aspects of pelagic ecosystem functioning are virtually unknown. Here, we argue for more attention to such research, and we marshal preliminary evidence that several mechanisms underlying diversity effects on ecosystem processes in marine benthic and terrestrial systems also may operate in pelagic systems. We review selected examples of how genetic, species, and functional group diversity may affect ocean ecosystem processes. We consider 3 types of examples that detail how (1) producer richness or composition can directly affect ecosystem processes, (2) consumer diversity can directly and indirectly affect these same processes, and (3) diversity at and below the species level can reduce variation of communities through time and enhance their resistance to perturbations. We suggest several promising avenues for assessing the role of biodiversity in pelagic ecosystems. Understanding and predicting responses of the global ocean ecosystem to accelerating climate and environmental change will be enhanced by more explicit and systematic attention to the functional diversity of microbial and macroscopic marine life.
\end{abstract}

KEY WORDS: Biodiversity $\cdot$ Ecosystem functioning $\cdot$ Pelagic $\cdot$ Production $\cdot$ Global change

\section{INTRODUCTION}

The biological composition and richness of most of the Earth's major ecosystems are changing as a result of harvesting, habitat destruction, pollution, exotic invasions, and climate change. Stimulated in part by these transformations, theoretical and empirical research in ecology has turned actively to the relationship between biodiversity and ecosystem functioning, i.e. aggregate, ecosystem-level processes such as production, element cycling, and trophic transfer (Chapin et al. 1997, Tilman 1999, Loreau et al. 2001). An influential series of field experiments, conducted primarily in terrestrial grass- lands, has demonstrated that the identity and number (richness) of plant species in a system can strongly influence primary productivity, efficiency of nutrient use, disease dynamics, invasibility by exotic species, and stability in the face of natural climate forcing and human perturbations (Tilman 1999, Loreau et al. 2001, 2002). Similarly, experiments in laboratory microcosms show that changing biodiversity in multilevel food webs also can have pervasive ecosystem impacts (Naeem \& Li 1997, Petchey et al. 2002).

Relative to terrestrial systems, the study of these issues in the marine pelagic zone is in its infancy, and there is little indication that this body of research 
has significantly influenced biological oceanography, although it is beginning to influence benthic ecology (Stachowicz et al. 1999, 2002, Duarte 2000, Emmerson et al. 2001, Bolam et al. 2002, Emmerson \& Huxham 2002, Duffy et al. 2003, 2005, Allison 2004, Solan et al. 2004, Waldbusser et al. 2004). This oversight is important for several reasons. First, it is increasingly clear that richness and composition of taxa in the marine pelagic zone may have a similarly strong influence on ecosystem processes to that observed on land. Second, the pelagic ecosystems of the open oceans are central mediators of planetary ecosystem processes with direct impacts on human welfare and economies, including carbon cycling and storage, greenhouse gas dynamics, harmful algal blooms, and human food production (Daily 1997, Falkowski et al. 1998, Balmford et al. 2002). Finally, and most importantly, human activities are demonstrably impacting the food web structure and taxonomic composition of even the most remote pelagic ecosystems on Earth (Shiomoto et al. 1997, Pauly et al. 1998, Beaugrand et al. 2002, Smith et al. 2003, Springer et al. 2003). It would be surprising indeed if these activities did not cause significant changes in the way that the ocean ecosystem functions, and, by extension, on the basic ecosystem services that it provides to human society (see Fig. 1).

In the present paper, we ask the question: Is biodiversity important to understanding the functioning of marine pelagic ecosystems? Although explicit experiments addressing this question are very rare, we argue that available evidence, mostly indirect, suggests that the answer is yes. Our aim is not a comprehensive review of such evidence, but a brief perspective that we hope will encourage more focused attention on links between biodiversity and pelagic ecosystem processes. By ecosystem functioning we mean the aggregate processes of central interest to biological oceanographers, such as primary and higher-level production, carbon and nutrient cycling and sequestration, and trophic transfer, as well as the stability of these processes over time and in the face of environmental change.

Previous research linking biodiversity to ecosystem functioning has focused primarily on species and functional group richness. We favor a concept of biodiversity expanded both downward and upward in the taxonomic hierarchy, to encompass genetic variation within species and variety of higher taxa, respectively. Such an expansion is especially important in marine ecosystems for 2 reasons. First, many marine ecosystem processes are dominated by microbes, many of which can only be distinguished genetically (Venter et al. 2004) and for which species concepts are vague. Indeed, with the advent of genomic approaches, functional differences among strains within nominal 'species' of marine phytoplankton and other microbes are increasingly evident (e.g. Knowlton \& Rohwer 2003, Rocap et al. 2003). Second, the oceans contain a far more diverse collection of kinds of organisms than occur on land, both from taxonomic and functional perspectives. Whereas nearly all terrestrial primary producers come from a single clade, the Embryophyta, marine autotrophs come from at least 8 evolutionarily ancient groups (Falkowski et al. 2004). Of the 33 animal phyla recognized by Margulis \& Schwartz (1988), 32 have marine representatives, and 15 of these are exclusively marine. Similarly, from a functional perspective, there are few, if any, terrestrial equivalents of suspension feeders or structure-forming sessile heterotrophs (e.g. some corals, sponges). Thus, both functional and higher-level taxonomic diversity tends to be higher in marine systems than on land or in fresh water.

Since few, if any, experiments have explicitly tested effects of diversity on functioning in marine pelagic ecosystems, our discussion relies on a mixture of examples from other habitats (including the marine benthos), combined with relevant ecological and natural history data on pelagic systems, to argue for the plausibility of diversity effects on ecosystem processes in pelagic systems. We build on the arguments of Verity \& Smetacek (1996, see also Verity et al. 2002) that top-down processes acting through the food web often have important, and still underappreciated, controlling influences on biomass, productivity, and composition of pelagic communities. This kind of 'vertical' diversity of trophic levels within food webs is clearly important, but we also argue that complementary use of resources and responses to environmental change, as well as interspecific facilitation by species within trophic levels (i.e. horizontal diversity) can enhance the consistency and stability of such basic ecosystem processes as primary production and nutrient cycling (see Fig. 2). We divide our examples into 3 sections that detail how (1) producer richness/ composition can directly affect ecosystem processes, (2) consumer diversity can have direct and indirect impacts on these same processes, and (3) diversity at and below the species level can reduce variation of communities through time and their resistance to perturbations. We conclude with suggestions of areas in which more explicit tests of diversity-functioning relationships might prove illuminating. We reiterate that our goal is not to exhaustively review the literature, but to explore how diversity might be important for pelagic ecosystem functioning and stimulate further research in this area.

\section{ECOSYSTEM CONSEQUENCES OF PHYTOPLANKTON AND MICROBIAL DIVERSITY}

The elemental stoichiometry of plankton biomass and seawater constitutes a complex feedback system 
fundamental to organic production and the global carbon cycle. Both macro- and micronutrient quotas in algae reflect consistent, anciently evolved differences in stoichiometry among major taxa of phytoplankton (Quigg et al. 2003). Although these quotas are to some degree plastic within species as growth conditions change, much of the variance in phytoplankton nutrient ratios is distributed among species or higher taxa. Moreover, theory (Klausmeier et al. 2004) and experiments (Sommer 1994) confirm that different nutrient profiles in the water column select for phytoplankton species with different stoichiometries. Changing phytoplankton species composition can, in turn, influence $\mathrm{CO}_{2}$ drawdown (Arrigo et al. 1999) and $\mathrm{C}$ sedimentation (Sieracki et al. 1993). These considerations suggest that spatial and temporal variance in rates of primary production and other ecosystem processes in the Earth's varied marine waters may be dampened by taxonomic and functional diversity within the phytoplankton (Fig. 1). Better understanding the functional significance of this diversity is especially timely, because community composition of both phytoplankton (Karl et al. 2001) and zooplankton (Beaugrand et al.
2002) is changing on a global scale, and these changes propagate up food chains on similarly large scales (Richardson \& Schoeman 2004).

Several examples of functional differentiation within species of marine microalgae illustrate these consequences nicely. In coastal Washington (USA), successive spring blooms of the centric diatom Ditylum brightwellii are comprised of genetically distinct clones, each of which grows best under different conditions (Rynearson \& Armbrust 2004, T. Rynearson unpubl. data). As a result, total biomass and production may be greater and extend over a longer time period than if the species represented a single, undifferentiated population. Experiments that examine the production of these strains in monocultures versus polycultures under realistically changing environmental conditions would be useful as a more rigorous test. Although the consequences of this producer diversity for animal populations have yet to be addressed, it is tempting to speculate that widening the window of the spring bloom may enhance the probability of survival for a variety of species that depend on it for food. A similar example from a benthic system involves the dinofla-

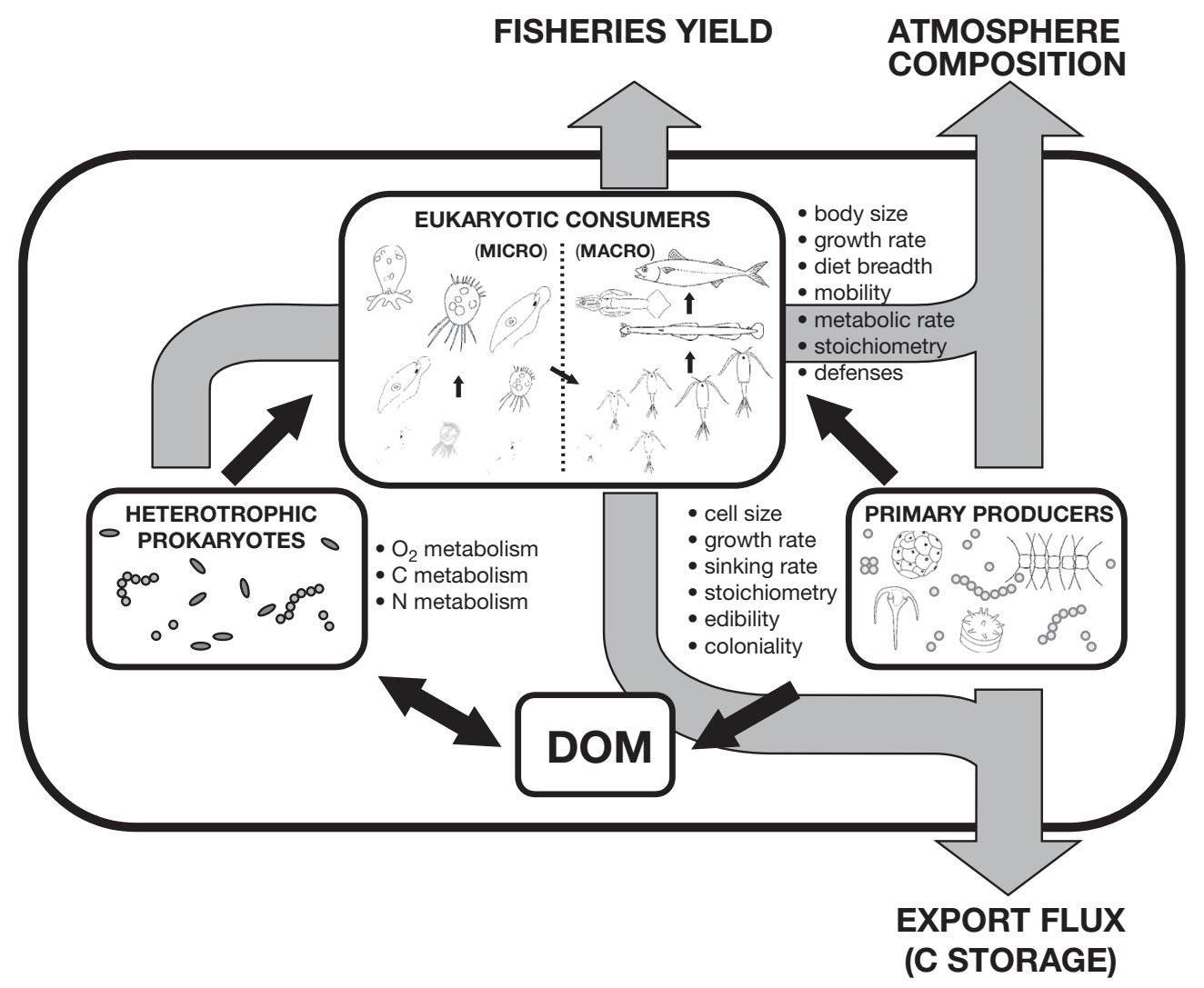

Fig. 1. Summary of some proposed links between pelagic biodiversity and marine ecosystem processes. A stylized food web, divided into 3 major components linked by trophic flows (black arrows), is shown. Beside each compartment is a list of traits likely to affect trophic flows, and gray arrows show influences of those compartments on ecosystem services. Compartments are presented as separate enclosed areas for clarity, although in reality ocean microorganisms span a metabolic continuum from pure autotrophs, through facultative autotrophs, mixotrophs, and facultative heterotrophs, to pure heterotrophs. DOM: dissolved organic matter 
gellate symbionts (zooxanthellae) on which scleractinian corals depend. These are a genetically diverse group of organisms that differ in their performance under different environmental conditions (e.g. Rowan et al. 1997, Knowlton \& Rohwer 2003). Some data suggest a trade-off among symbiont genotypes in the ability to resist bleaching versus their benefit to corals under 'normal' conditions (see review by Sotka \& Thacker 2005). If such trade-offs are confirmed, then maintaining a diversity of symbionts (or at least having a diverse pool of symbionts to draw from) may enhance the growth and persistence of reef-building corals and the entire ecosystem that depends on them.

Analogous genetic differentiation occurs within photosynthetic marine prokaryotes, which play important roles in primary production (Partensky et al. 1999) and nitrogen fixation (Karl 1999, Zehr et al. 2001) in most oceanic environments. Recent genomic studies suggest that different strains within a 'species' of marine microbe differ in the forms of nitrogen they can use (Dufresne et al. 2003, Palenik et al. 2003, Rocap et al. 2003), implying that a diverse assemblage may be able to utilize available nutrients more completely and efficiently, thereby increasing primary production, especially when integrated over time, space, or depth. Functional diversity at the microbial level appears to have been vastly underestimated historically, and we suspect that evidence for the importance of this diversity to ecosystem processes will continue to mount. Experimental approaches are needed to complement existing comparative data, but experiments in terrestrial and marine benthic systems show that when species have temporally or spatially complementary distributions, diversity can increase total resource use and enhance production (e.g. Tilman et al. 1996, Stachowicz et al. 2002).

\section{BIODIVERSITY AND THE FUNCTIONING OF OCEAN FOOD WEBS}

Trophic processes generally, and fishery production specifically, are strongly influenced by the specific routes and efficiency with which primary production fluxes through the food web (Pauly \& Christensen 1995, Fig. 1). Taxonomic composition of the plankton influences such trophic transfer, as well as vertical carbon flux (Lasker 1975, Parsons et al. 1984, Michaels \& Silver 1988). But trophic transfer and the strength of top-down control are predicted to depend not only on the types, but also on the number of producer and consumer taxa present and the degree to which consumers are specialists versus generalists (Duffy 2002, Thébault \& Loreau 2003). More diverse primary producer assemblages are expected to be more resistant to grazing control, primarily because they are more likely to contain grazer-resistant taxa that can dominate when edible taxa are depleted (Leibold et al. 1997, Duffy 2002). Several lines of evidence support this theory for aquatic systems. First, laboratory experiments show that naturally diverse freshwater algal assemblages are much more resistant to grazer control than unialgal cultures of edible algae (Steiner 2001). Second, a recent meta-analysis of 172 experiments showed that grazing impact on total biomass of benthic microalgae was reduced as algal species richness increased (Hillebrand \& Cardinale 2004). Similarly, at the next trophic level up, experimental data show that a diverse assemblage of benthic crustacean grazers lost less biomass to predators, on average, than did single grazer populations (Duffy et al. 2005). These results hint that gross ecological efficiency, i.e. the proportion of production at one trophic level that is converted to production at the next level in the food web, can depend significantly on the composition and richness of taxa within levels.

These examples show that prey diversity can reduce the efficiency of consumers, and thus dampen their impact on prey biomass. Conversely, diversity of consumers could increase their aggregate efficiency of resource use and, thus, increase both consumer (secondary) production and strength of top-down control (Holt \& Loreau 2002). This could occur either by resource partitioning, as different predators suppress different prey, or by predator facilitation, in which one predator species alters prey behavior, making it more susceptible to a second predator (see Ives et al. 2005 for a fuller discussion). Alternatively, antagonistic intraguild interactions in which predators consume other predators as well as herbivores could lead to reduced herbivore control with increasing predator diversity (Finke \& Denno 2004, Ives et al. 2005). In pelagic systems, however, predators and prey often share the same spatial refuge from a common top predator, and the resulting predator-induced behavioral shifts may turn such intraguild interactions into predator facilitation (Fisken et al. 2005). For example, predator facilitation might occur when copepods are subject to both visual predators (e.g. fishes) at the surface and non-visual predators (e.g. chaetognaths, ctenophores) that remain at depth during the day to avoid fish predation (Ohman 1990). In this case, the reverse diel migration strategy employed by copepods to avoid invertebrate predators leads to an increase in consumption by fish predators at the surface (Fisken et al. 2005). Thus, synergistic interactions among predators may lead to enhanced herbivore control and increases in phytoplankton biomass.

While consumer diversity effects have not been explicitly tested in pelagic systems, they receive some 
experimental support from other systems. For example, mesocosm experiments in a seagrass system showed that increasing species richness of invertebrate grazers enhanced both their own secondary production and their impact on the algal resource (Duffy et al. 2003, 2005). Similarly, kelp forest mesocosm experiments showed that increasing predator diversity enhanced the suppression of herbivorous invertebrates, because of complementary effects of predators on different herbivores, resulting in greater kelp biomass (Byrnes et al. 2006). Also, increased diversity of suspension-feeding stream invertebrates enhanced collective feeding efficiency and particle capture by creating a more heterogeneous substratum that enhanced turbulent flow and prevented food depletion in the boundary layer (Cardinale et al. 2002). As discussed previously, enhancement of production and resource use with increasing diversity is also commonly (although not always) found within basal trophic levels in both aquatic and terrestrial systems (Hector et al. 1999, Naeem et al. 2000, Tilman et al. 2001, Stachowicz et al. 2002), suggesting that a positive relationship between diversity and resource use commonly occurs. If similar effects of biodiversity on trophic transfer do, in fact, occur in pelagic systems, maintaining diversity might lead, for example, to more consistently high fishery yields. The low fishery yields of highly diverse, tropical gyres may at first seem inconsistent with this conclusion. But productivity of these-and all-ecosystems is ultimately constrained by resource input. Theory and limited evidence suggest that, at a given level of resource input, diversity influences how efficiently available resources are used.

Finally, a recent study confirms that explicitly recognizing functional diversity within a trophic level can fundamentally alter our conclusions about how ocean food webs work. Meta-analyses of experiments in marine pelagic systems have found that predator effects appear to attenuate at intermediate levels in the food web, with little effect on phytoplankton (Micheli 1999, Shurin et al. 2002). However, detailed analysis of an expanded data base shows that effects of predator deletions in the marine pelagic do often cascade to phytoplankton biomass, but the sign of their influence on phytoplankton depends on whether they cascade through a 3- or 4-link food chain, which in turn depends on cell size (hence, taxonomic composition) of the dominant taxa (Stibor et al. 2004). Because earlier studies averaged results from 3- and 4 -link chains, the strong influence of predators on phytoplankton was masked. The revised conclusion that top-down control has pervasive impacts on marine pelagic food webs is also consistent with field data (Shiomoto et al. 1997).

\section{BIODIVERSITY AND MARINE ECOSYSTEM STABILITY}

Human welfare depends on the stability of both ecosystems and economies (Armsworth \& Roughgarden 2003). Theory (Tilman et al. 1997, Yachi \& Loreau 1999) predicts that increasing species richness can stabilize ecosystem processes through time and space, and in the face of perturbations (Fig. 2). Experiments in terrestrial grasslands (Tilman \& Downing 1994, Tilman 1996) and aquatic protist communities (Naeem \& Li 1997) support this theory, and a few marine benthic experiments suggest that similar patterns may hold in the sea (Stachowicz et al. 2002, Stachowicz \& Byrnes
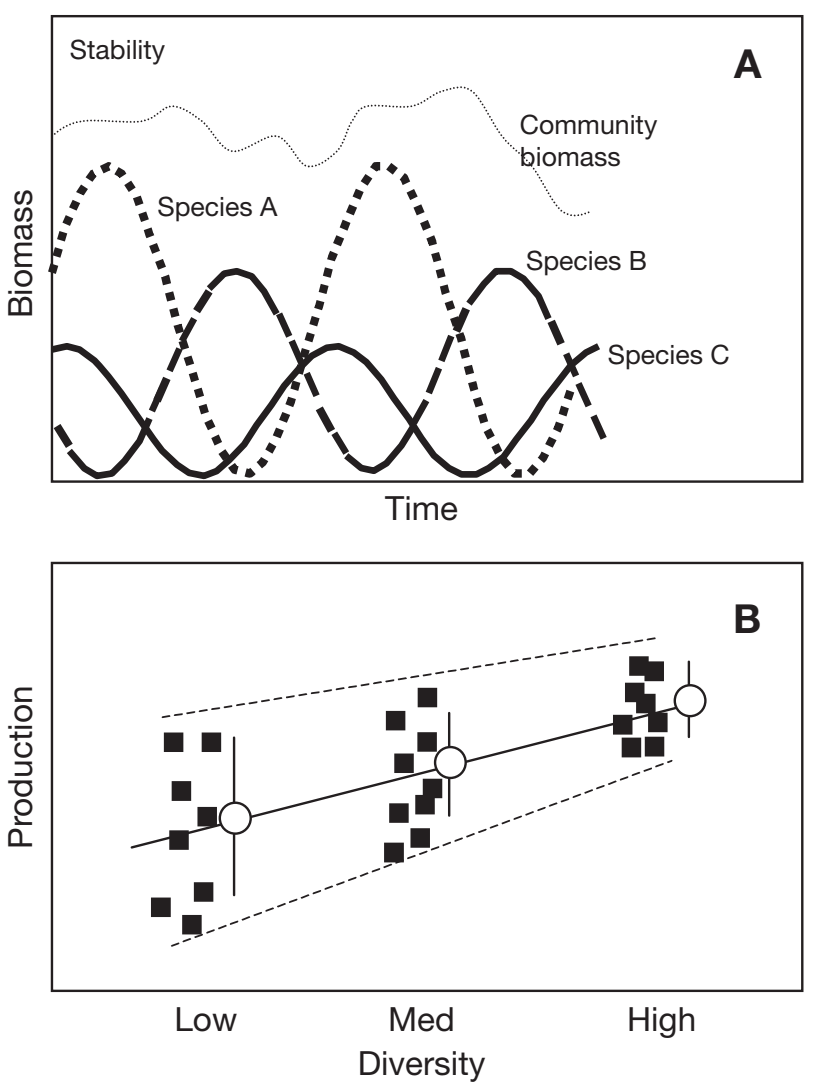

Fig. 2. Some proposed mechanisms linking biodiversity to ecosystem functioning. (A) Stability: in a hypothetical system, temporal variation in aggregate trophic level biomass is reduced relative to variability of individual species (see Stachowicz et al. 2002 for a real example). (B) Productivity: mean biomass production is greater in hypothetical assemblages with higher diversity, because species interact to enhance aggregate productivity (complementarity) and/or because highly productive species are more likely to be present in a diverse assemblage (sampling effect) (see Duffy et al. 2003 for a real example). $\mathbf{\square}$ : means for individual species or combinations; O: mean (with estimate of variance) of all combinations at that level of diversity; —_: trend of mean productivity with species richness; - - - - bounds of the range of productivity. Note that variance in productivity is higher in diverse mixtures than at low diversity (e.g. for single species) as in (A) 
2006, in this Theme Section). In general, however, marine studies have been more heterogeneous in their approach to this question, with increased focus on diversity below the species level. Several disparate lines of empirical evidence suggest that marine ecosystem stability may be enhanced by high genetic or phenotypic diversity within key species. Field manipulations of seagrass (Zostera marina) genotypic diversity showed that higher diversity enhanced community resistance to disturbance by grazing geese and the stress associated with transplantation, resulting in more stable seagrass biomass and higher abundances of invertebrates and other associated species (Hughes \& Stachowicz 2004); similar stabilizing effects of genetic diversity against temperature extremes were demonstrated in Baltic eelgrass (Reusch et al. 2005). In another example, individual salmon stocks fluctuated in response to year-to-year environmental variation, but the total salmon catch was buffered from these fluctuations, because, when one stock had low abundance for a series of years, another was above average for those years (Hilborn et al. 2003). As a result, the genetic composition of the overall salmon catch fluctuated greatly from year to year, but the total catch (total fish abundance) was more constant. These stabilizing effects of genetic diversity are remarkably similar to effects of species diversity in terrestrial grasslands and sessile marine invertebrate communities. In these systems, results generally have shown that as species diversity increases, the stability of individual species' abundances decreases, but stability of overall community biomass increases (Tilman 1999, Stachowicz et al. 2002). These results are also consistent with theory that predicts that negative covariances among species in their response to environmental fluctuations should produce a stabilizing effect of diversity on total community biomass (Tilman 1999).

\section{WHAT SHOULD WE DO NOW?}

In the preceding sections we have outlined areas in which existing data suggest that biodiversity should affect pelagic ecosystem processes and have highlighted a few areas in which further experimentation is needed. Given how few rigorous experiments have been conducted on this topic, virtually any effort promises to advance our understanding, and we encourage experimentation to complement existing correlational and anecdotal evidence. Indeed the combination of observational and experimental approaches has proven quite profitable in terrestrial and marine benthic systems (e.g. Tilman et al. 1996, Levine 2000, Stachowicz et al. 2002, Stachowicz \& Byrnes 2006). However, there are some cautions to be heeded and lessons to be learned from recent debate on the interpretation of such experiments in terrestrial systems. Early work manipulating 'biodiversity' sometimes confounded the effects of species composition (identity) and species richness (number). For example, experiments in which low-diversity treatments are created by deleting some portion of the species from an intact high-diversity community are ecologically realistic in that they mimic species extinction, but they cannot distinguish between effects of diversity per se (i.e. interactions among species) and effects of particularly important species (Huston 1997). Such effects can be distinguished by including treatments in which each species (or genotype, functional group) in the intact, diverse community is also grown in monoculture, allowing the comparison of species singly and in mixture. In particular, this type of design is helpful in distinguishing between effects of diversity due to complementary species properties versus the increasing probability of including a species with dominant effects as diversity increases, i.e. the sampling effect (see Huston 1997, Tilman et al. 1997, Allison 1999, Schmid et al. 2002, for more discussion on the design of these experiments).

A second lesson emerging from early research in this field is that the most powerful concept of ecosystem functioning requires considering multiple response variables. Most early grassland experiments focused on the single response variable of aggregate plant biomass accumulation, considered a proxy for productivity in these systems with relatively low grazing pressure. In marine systems, standing biomass of algae is a poor proxy for productivity, since production is often cropped as rapidly as it is produced. The absence of significant species richness effects on productivity in several terrestrial experiments, the commonness of the sampling effect in others, and the general saturation of productivity at relatively low species richness has led some authors to argue that species diversity has little appreciable influence on ecosystem functioning (e.g. Schwartz et al. 2000, Wardle et al. 2000). But this conclusion may be an artifact of the narrow focus on a single response variable: species influence many aspects of ecosystem functioning, and particular functions are often most strongly influenced by different species (Eviner \& Chapin 2003). Hence, even when one process (e.g. primary productivity) is dominated by a single species in a diverse mixture, the overall functioning of the diverse system may nevertheless differ considerably from that of any single monoculture. This phenomenon has been termed the 'multivariate dominance effect' (Duffy et al. 2003). It is supported by experimental data from a seagrass system, in which different grazer species maximized grazing pressure, secondary production, and sedi- 
mentary organic carbon content, with the diverse mixture showing comparably high values of each of these response variables (Duffy et al. 2003). Similarly, particular algal foods often maximize grazer growth, whereas others maximize survival, and still others reproduction, such that total grazer production may be highest when a diversity of foods is present (e.g. Cruz-Rivera \& Hay 2000, Dam \& Lopes 2003). This phenomenon is likely to be common, as evidenced by the analysis of Petchey \& Gaston (2002), who showed that as more functional traits (e.g. height, leaf $\mathrm{N}$ content, palatability, temperature tolerance) were incorporated into their multivariate index of functional diversity, the relationship between species richness and functional diversity became more linear. Yet the potential role of the multivariate dominance effect in linking biodiversity to ecosystem functioning remains unstudied empirically.

Finally, a fundamental difference between marine and terrestrial systems is the larger role of advection and habitat connectivity in marine systems. Several recent reviews have emphasized the potential influence of advection and flow on relationships between aquatic biodiversity and ecosystem processes (Biles et al. 2003, Covich et al. 2004, Giller et al. 2004). Further, benthic microcosm studies suggest that the strength of the biodiversity effect may weaken in open compared to closed systems (Matthiessen et al. in press) Given the fluid nature of the pelagic ecosystem, this is clearly an important consideration that underscores the importance of extending studies on biodiversityecosystem functioning, historically conducted at small spatial scales, to incorporate meta-community dynamics and linkages between different habitats (e.g. Loreau et al. 2003), particularly benthic-pelagic coupling.

Building on insights from pioneering terrestrial and microbial experiments and considering the unique aspects of ocean ecosystems, we offer the following, non-comprehensive list of suggestions for future research on how biodiversity may mediate pelagic ecosystem processes.

What is the importance of changing biodiversity relative to the demonstrated importance of physical forcing in influencing ecosystem structure and function? Few experiments have attempted to quantify the relative importance of changing diversity compared with typical variance in nutrient loading, temperature, and light levels for ecosystem process rates. Somewhat conflicting results have emerged from those that are available (e.g. Naeem \& Li 1997, Reich et al. 2004), suggesting the need for broader understanding of the conditions under which each of these factors exerts a dominant influence on ecosystem processes.
How does phytoplankton biodiversity-genotypes, species, higher taxa-influence production dynamics and trophic transfer? Phytoplankton biomass is commonly measured as bulk chlorophyll. But variance in both environmental tolerances and intrinsic growth rates among species, higher taxa, and even among genotypes of phytoplankton are increasingly well documented. How important is such functional diversity in influencing the magnitude of production, spatial and temporal extent of blooms, and thus the ability of higher trophic levels to exploit them? To what extent are the patterns and mechanisms elucidated in terrestrial plant assemblages even applicable to the other $70 \%$ of the Earth's surface? There are fundamental differences in mechanisms of resource use (nutrient uptake), relative biomass of photosynthetic versus structural material, and biomass turnover rates between the dominant producers on land (vascular plants) and in the sea (algae). Concordance of results from marine versus terrestrial systems (e.g. Bruno et al. 2005) would greatly increase the robustness of any conclusions.

What is the role of bacterial diversity in dissolved organic carbon dynamics? Dissolved organic carbon is the largest reservoir of organic carbon in the oceans, analogous to the humic fraction of soil organic matter. This material is a complex mixture of labile and highly refractory components, and processing it likely requires a suite of metabolic adaptations. In laboratory experiments, diverse bacterial assemblages can decompose a greater range of organic substrates (Naeem et al. 2000). The growing power of genomics in identifying bacterial genotypes should make it possible to begin testing whether similar phenomena are important in ocean ecosystem processes.

How does diversity of higher order consumers affect ecosystem functioning? Given that extinctions in the sea (and elsewhere) tend to be biased toward large consumers (Pauly et al. 1998, Jackson et al. 2001), a better understanding of the consequences of changing predator diversity for biomass, productivity, and community composition of lower trophic levels is critical. Further, the effects of diversity at one level often depend on the diversity at others (e.g. Duffy 2002, Gamfeldt et al. 2005), suggesting that, where possible, a factorial approach to diversity manipulations across trophic levels might prove insightful. Despite clear reductions in predator diversity and abundance in the sea (Myers \& Worm 2003, Worm et al. 2005), ecologically meaningful predators still play important roles in many if not most marine ecosystems. This, combined with the long history of studying trophic interactions in marine systems, suggests that marine ecologists are well poised to address this question. 
What are the economic costs of declining biodiversity? Oceanic processes are linked in a variety of ways to issues of importance to society, including human health, food production, water quality, greenhouse gas dynamics, and harmful algal blooms (Daily 1997, Falkowski et al. 1998, Balmford et al. 2002). If biodiversity is found to affect the specific ocean processes involved, then perhaps we can begin to quantify the direct economic 'costs' of declines in marine biodiversity.

A fundamental challenge in addressing all of these questions involves the bidirectional causal influences between biodiversity, productivity, and stability (Loreau et al. 2001, Naeem 2002, Worm \& Duffy 2003). This bidirectionality means that observational and correlational studies will need to be coupled with experimental manipulations to test definitively the relative roles of community structure (including diversity) versus extrinsic forcing in mediating rates of ecosystem processes.

\section{Concluding remarks}

The oceans harbor tremendous biological diversity. To render this diversity manageable, models of ocean ecosystem processes historically employed simplified food web structures, often with highly aggregated compartments. It is clearly impossible to account for every species in such models (Frost 1984, deYoung et al. 2004), and there is an inherent trade-off between increasing realism versus the inability to parameterize complex models. Nevertheless, the examples discussed above emphasize that there is a strong incentive to incorporate more realistic functional diversity of marine pelagic organisms in ocean ecosystem models. Several oceanographers have recently emphasized the necessity of doing so, and recent advances in this direction have been quite promising (e.g. Armstrong 2003, Gentleman et al. 2003, Le Quéré et al. 2005). Even slight disaggregation of traditional 'boxes' in these models can lead to dramatic changes in model predictions or experimental results (e.g. Stibor et al. 2004), suggesting that experimental approaches that either use simple systems with few species or that aggregate species into a manageable number of functional groups might be a profitable place to begin. Incorporating biodiversity into already complex ecosystem and biogeochemical models will be challenging, but is of pressing importance in the face of accelerating global environmental change. As one example, consider that serious proposals have been put forward to mitigate rising atmospheric $\mathrm{CO}_{2}$ levels by fertilizing remote ocean regions with iron. These proposals rely implicitly on a simplistic box- model concept of the ocean, in which carbon is taken up at constant stoichiometry by a homogeneous 'phytoplankton' compartment and transported to the deep ocean via sedimentation, either directly or as fecal pellets from a homogeneous 'grazer' compartment. Yet an extensive body of research shows that nutrient addition routinely leads not only to increases in biomass of primary producers, but also to changes in phytoplankton community composition (Leibold et al. 1997, Boyd et al. 2000, Landry 2002). Lehman (1988) used a simple model to show that dividing the phytoplankton into even a few species that differ realistically in nutrient quotas and grazing susceptibility can change substantially the magnitude and even the sign of the system's response to iron (or presumably other nutrient) addition. Field data indeed confirm that $\mathrm{CO}_{2}$ drawdown in the Southern Ocean depends strongly on phytoplankton species composition (Arrigo et al. 1999).

These examples indicate that our understanding of responses of the ocean ecosystem to anthropogenic perturbations will profit from the growing trend toward incorporating diversity in ocean ecosystem models. There is reason for optimism. Hulot et al. (2000) developed a model that divided lake phytoplankton into edible and inedible compartments, and showed that the model successfully predicted the responses of 3 trophic levels to manipulation in field experiments. Stibor et al. (2004) similarly showed that simply dividing phytoplankton into small- and largecelled taxa explained major variance in strength of marine pelagic trophic cascades. Even on the scale of regional seas and ocean basins, size-based models of food web interactions and nutrient use have successfully reproduced spatial and temporal patterns of production and carbon flux (e.g. Blackford \& Burkill 2002, Moore et al. 2002). While matching models to empirical data will not always be straightforward, these examples confirm that incorporating functional diversity into ocean ecosystem models can substantially enhance their power. The recent advances in ocean ecosystem modeling also suggest that ecologists interested in biodiversity-functioning relationships can learn from the successes of oceanographers in seeking to identify the minimal diversity necessary to reproduce-and predict-realistic patterns of ecosystem functioning and biogeochemistry.

Acknowledgements. We thank M. Solan for the invitation to contribute to this Theme Section; the NCEAS Working Group on Marine Biodiversity and Ecosystem Services for stimulating discussion; H. Ducklow, R. Hughes, and 4 anonymous reviewers for comments that improved the manuscript; and the NSF for support (OCE 03-52343 to J.E.D. and OCE 0351778 to J.J.S.). This paper is Contribution 2730 from the Virginia Institute of Marine Science. 


\section{LITERATURE CITED}

Allison GW (1999) The implications of experimental design for biodiversity manipulations. Am Nat 153:25-45

Allison GW (2004) The influence of species diversity and stress intensity on community resistance and resilience. Ecol Monogr 74:117-134

Armstrong RA (2003) A hybrid spectral representation of phytoplankton growth and zooplankton response: the 'control rod' model of plankton interaction. Deep-Sea Res II 50:2895-2916

Armsworth PR, Roughgarden JE (2003) The economic value of ecological stability. Proc Natl Acad Sci USA 100: $7147-7151$

Arrigo KR, Robinson DH, Worthen DL, Dunbar RB, DiTullio GR, VanWoert M, Lizotte MP (1999) Phytoplankton community structure and the drawdown of nutrients and $\mathrm{CO}_{2}$ in the Southern Ocean. Science 238:365-367

Balmford A, Bruner A, Cooper P, Costanza R and 15 others (2002) Economic reasons for conserving wild nature. Science 297:950-953

Beaugrand G, Reid PC, Ibaez F, Lindley JA, Edwards M (2002) Reorganization of North Atlantic marine copepod biodiversity and climate. Science 296:1692-1694

Biles CL, Solan M, Isaksson I, Paterson DM, Emes C, Raffaelli DG (2003) Flow modifies the effect of biodiversity on ecosystem functioning: an in situ study of estuarine sediments. J Exp Mar Biol Ecol 285/286:165-177

Blackford JC, Burkill PH (2002) Planktonic community structure and carbon cycling in the Arabian Sea as a result of monsoonal forcing: the application of a generic model. J Mar Syst 36:239-267

Bolam SG, Fernandes TF, Huxham M (2002) Diversity biomass and ecosystem processes in the marine benthos. Ecol Monogr 72:599-615

Boyd PW, Watson AJ, Law CS, Abraham AR and 31 others (2000) A mesoscale phytoplankton bloom in the polar Southern Ocean stimulated by iron fertilization. Nature 407:695-702

Bruno JF, Boyer KE, Duffy JE, Lee SC, Kertes JS (2005) Effects of macroalgal species identity and richness on primary production in benthic marine communities. Ecol Lett 8:1165-1174

Byrnes J, Stachowicz JJ, Hultgren KM, Hughes AR, Olyarnik SV, Thornber CS (2006) Predator diversity strengthens trophic cascades in kelp forests by modifying herbivore behaviour. Ecol Lett 9:61-71

Cardinale BJ, Palmer MA, Collins SL (2002) Species diversity enhances ecosystem functioning through interspecific facilitation. Nature 426:426-429

Chapin FS III, Walker BH, Hobbs RJ, Hooper DU, Lawton JH, Sala OE, Tilman D (1997) Biotic control over the functioning of ecosystems. Science 277:500-504

Covich AR, Austen MC, Bärlocher F, Chauvet E and 8 others (2004) The role of biodiversity in the functioning of freshwater and marine benthic ecosystems. BioScience 54: $767-775$

Cruz-Rivera E, Hay ME (2000) The effects of diet mixing on consumer fitness: macroalgae, epiphytes, and animal matter as food for marine amphipods. Oecologia 123: $252-264$

Daily GC (ed) (1997) Nature's services: societal dependence on natural ecosystems. Island Press, Washington, DC

Dam HG, Lopes RM (2003) Omnivory in the calanoid copepod Temora longicornis: feeding, egg production and egg hatching rates. J Exp Mar Biol Ecol 292:119-137

deYoung B, Heath M, Werner F, Chai F, Megrey B, Monfray P
(2004) Challenges of modeling ocean basin ecosystems. Science 304:1463-1466

Duarte CM (2000) Marine biodiversity and ecosystem services: an elusive link. J Exp Mar Biol Ecol 250:117-131

Duffy JE (2002) Biodiversity and ecosystem function: the consumer connection. Oikos 99:201-219

Duffy JE, Canuel EA, Richardson JP (2003) Grazer diversity and ecosystem functioning in seagrass beds. Ecol Lett 6: $1-9$

Duffy JE, Richardson JP, France KE (2005) Ecosystem consequences of diversity depend on food chain length in estuarine vegetation. Ecol Lett 8:301-309

Dufresne A, Salanoubat M, Partensky F, Artiguenave F and 17 others (2003) Genome sequence of the cyanobacterium Prochlorococcus marinus SS120, a nearly minimal oxyphototrophic genome. Proc Natl Acad Sci USA 100: 10020-10025

Emmerson M, Huxham M (2002) How can marine ecology contribute to the biodiversity-ecosystem functioning debate? In: Loreau M, Naeem S, Inchausti P (eds) Biodiversity and ecosystem functioning. Oxford University Press, New York, p 139-146

Emmerson MC, Solan, M, Emes C, Paterson DM, Raffaelli D (2001) Consistent patterns and the idiosyncratic effects of biodiversity in marine systems. Nature 411:73-77

Eviner VT, Chapin FS III (2003) Functional matrix: a conceptual framework for predicting multiple plant effects on ecosystem processes. Annu Rev Ecol Evol Syst 34:455-485

Falkowski PG, Barber RT, Smetacek V (1998) Biogeochemical controls and feedbacks on ocean primary production. Science 281:200-206

Falkowski PG, Katz ME, Knoll AH, Quigg A, Raven JA, Schofield O, Taylor FJR (2004) The evolution of modern eukaryotic phytoplankton. Science 305:354-360

Finke DL, Denno RF (2004) Predator diversity dampens trophic cascades. Nature 429:407-410

Fiskin O, Eliassen S, Titelman J (2005) Multiple predators in the pelagic: modeling behavioral cascades. J Anim Ecol 74:423-429

Frost BW (1984) Utilization of phytoplankton production in the surface layer. In: Global ocean flux study: proceedings of a workshop. National Academy Press, Washington, DC, p 125-135

Gamfeldt L, Hillebrand H, Jonsson PR (2005) Species richness changes across two trophic levels simultaneously affect prey and consumer biomass. Ecol Lett 8:696-703

Gentleman W, Leising A, Frost B, Strom S, Murray J (2003) Functional responses for zooplankton feeding on multiple resources: a review or assumptions and biological dynamics. Deep-Sea Res II 50:2847-2875

Giller PS, Hillebrand H, Berninger UG, Gessner MO and 8 others (2004) Biodiversity effects on ecosystem functioning: emerging issues and their experimental test in aquatic environments. Oikos 104:423-436

Hector A, Schmid B, Beierkuhnlein C, Caldeira MC and 30 others (1999) Plant diversity and productivity experiments in European grasslands. Science 286:1123-1127

Hilborn R, Quinn TP, Schindler DE, Rogers DE (2003) Biocomplexity and fisheries sustainability. Proc Natl Acad Sci USA 100:6564-6568

Hillebrand H, Cardinale BJ (2004) Consumer effects decline with prey diversity. Ecol Lett 7:192-201

Holt RD, Loreau M (2002) Biodiversity and ecosystem functioning: the role of trophic interactions and the importance of system openness. In: Kinzig AP, Pacala SW, Tilman D (eds) The functional consequences of biodiversity. Princeton University Press, Princeton, NJ, p 246-262 
Hughes AR, Stachowicz JJ (2004) Genetic diversity enhances the resistance of a seagrass ecosystem to disturbance. Proc Natl Acad Sci USA 101:8998-9002

Hulot FD, Lacroix G, Lescher-Moutoué F, Loreau M (2000) Functional diversity governs ecosystem response to nutrient enrichment. Nature 405:340-344

Huston MA (1997) Hidden treatments in ecological experiments: re-evaluating the ecosystem function of biodiversity. Oecologia 110:449-460

Ives AR, Cardinale BJ, Snyder WE (2005) A synthesis of subdisciplines: predator-prey interactions, and biodiversity and ecosystem functioning. Ecol Lett 8:102-116

Jackson JBC, Kirby MX, Berger WH, Bjorndal KA and 15 others (2001) Historical overfishing and the recent collapse of coastal ecosystems. Science 293:629-638

Karl DM (1999) A sea of change: biogeochemical variability in the North Pacific subtropical gyre. Ecosystems 2: $181-214$

Karl DM, Bidigare RR, Letelier RM (2001) Long-term changes in plankton community structure and the productivity of the North Pacific subtropical gyre. Deep-Sea Res II 48: $1449-1470$

Klausmeier CA, Litchman E, Daufresne T, Levin SA (2004) Optimal nitrogen-to-phosphorus stoichiometry of phytoplankton. Nature 429:171-174

Knowlton N, Rohwer F (2003) Multispecies microbial mutualisms on coral reefs: the host as a habitat. Am Nat 162: 51-62

Landry MR (2002) Integrating classical and microbial food web concepts: evolving views from the open-ocean tropical Pacific. Hydrobiologia 480:29-39

Lasker R (1975) Field criteria for survival of anchovy larvae: the relation between inshore chlorophyll maximum layers and successful first feeding. Fish Bull 73:453-462

Lehman JT (1988) Ecological principles affecting community structure and secondary production by zooplankton in marine and freshwater environments. Limnol Oceanogr 33:931-945

Leibold MA, Chase JM, Shurin JB, Downing AL (1997) Species turnover and the regulation of trophic structure. Annu Rev Ecol Syst 28:467-494

Le Quéré C, Harrison SP, Prentice IC, Buitenhuis ET and 16 others (in press) Ecosystem dynamics based on plankton functional types for global ocean biogeochemistry models. Global Change Biol 11:2016-2040

Levine JM (2000) Species diversity and biological invasions: relating local process to community pattern. Science 288: 852-854

Loreau M, Naeem S, Inchausti P, Bengtsson J and 8 others (2001) Biodiversity and ecosystem functioning: current knowledge and future challenges. Science 294:804-808

Loreau M, Naeem S, Inchausti P (eds) (2002) Biodiversity and ecosystem functioning. Synthesis and perspectives. Oxford University Press, Oxford

Loreau M, Mouquet N, Gonzalez A (2003) Biodiversity as spatial insurance in heterogeneous landscapes. Proc Natl Acad Sci USA 100:12765-12770

Margulis L, Schwartz KV (1988) Five kingdoms: an illustrated guide to the phyla of life on Earth, 2nd edn. Island Press, Washington, DC

Matthiessen B, Gamfeldt L, Jonsson P, Hillebrand H (in press) Effects of grazer richness and composition on algal biomass in a closed and open marine system. Ecology

Michaels AF, Silver MW (1988) Primary production, sinking fluxes and the microbial food web. Deep-Sea Res 35: 473-490

Micheli F (1999) Eutrophication, fisheries, and consumer- resource dynamics in marine pelagic ecosystems. Science 285:1396-1398

Moore JK, Doney SC, Kleypas JA, Glover DM, Fung IY (2002) An intermediate complexity marine ecosystem model for the global domain. Deep-Sea Res II 49:403-462

Myers RA, Worm B (2003) Rapid worldwide depletion of predatory fish communities. Nature 423:280-283

Naeem S (2002) Ecosystem consequences of biodiversity loss: the evolution of a paradigm. Ecology 83:1537-1552

Naeem S, Li S (1997) Biodiversity enhances ecosystem predictability. Nature 390:507-509

Naeem S, Hahn DR, Schuurman G (2000) Producer-decomposer co-dependency influences biodiversity effects. Nature 403:762-764

Ohman MD (1990) The demographic benefits of diel vertical migration by zooplankton. Ecol Monogr 60:257-281

Palenik B, Brahamsha B, Larimer FW, Land M and 11 others (2003) The genome of a motile marine Synechococcus. Nature 424:1037-1042

Parsons TR, Takahashi M, Hargrave B (1984) Biological oceanographic processes, 3rd edn. Pergamon, Oxford

Partensky F, Hess WR, Vaulot D (1999) Prochlorococcus, a marine photosynthetic prokaryote of global significance. Microbiol Mol Biol Rev 63:106-127

Pauly D, Christensen V (1995) Primary production required to sustain global fisheries. Nature 374:255-257

Pauly D, Christensen V, Dalsgaard J, Froese R, Torres F Jr (1998) Fishing down marine food webs. Science 279: 860-863

Petchey OL, Gaston KJ (2002) Functional diversity (FD), species richness and community composition. Ecol Lett 5: 402-411

Petchey OL, Morin PJ, Hulot FD, Loreau M, McGrady-Steed J, Naeem S (2002) Contributions of aquatic model systems to our understanding of biodiversity and ecosystem functioning. In: Kinzig AP, Pacala SW, Tilman D (eds) The functional consequences of biodiversity. Princeton University Press, Princeton, NJ, p 127-138

Quigg A, Finkel ZV, Irwin AJ, Rosenthal Y and 5 others (2003) The evolutionary inheritance of elemental stoichiometry in marine phytoplankton. Nature 425:291-294

Reich PB, Tilman D, Naeem S, Ellsworth DS, Knops J, Craine J, Wedin D, Trost J (2004) Species and functional group diversity independently influence biomass accumulation and its response to $\mathrm{CO}_{2}$ and N. Proc Natl Acad Sci USA 101:10101-10106

Reusch TBH, Ehlers A, Hämmerli A, Worm B (2005) Ecosystem recovery after climatic extremes enhanced by genotypic diversity. Proc Natl Acad Sci USA 102:2826-2831

Richardson AJ, Schoeman DS (2004) Climate impact on plankton ecosystems in the northeast Atlantic. Science 305:1609-1612

Rocap G, Larimer FW, Lamerdin J, Malfatti S and 20 others (2003) Genome divergence in two Prochlorococcus ecotypes reflects oceanic niche differentiation. Nature 424: 1042-1047

Rowan R, Knowlton N, Baker A, Jara J (1997) Landscape ecology of algal symbionts creates variation in episodes of coral bleaching. Nature 388:265-269

Rynearson T, Armbrust V (2004) Genetic differentiation among populations of the planktonic marine diatom Ditylum brightwellii (Bacillariophyceae). J Phycol 40:34-43

Schmid B, Joshi J, Schläpfer F (2002) Empirical evidence for biodiversity-ecosystem functioning relationships. In: Kinzig AP, Pacala SW, Tilman D (eds) The functional consequences of biodiversity. Princeton University Press, Princeton, NJ, p 120-150 
Schwartz MW, Brigham CA, Hoeksema JD, Lyons KG, Mills $\mathrm{MH}$, van Mantgem PJ (2000) Linking biodiversity to ecosystem function: implications for conservation ecology. Oecologia 122:297-305

Shiomoto A, Tadokoro K, Nagasawa K, Ishida Y (1997) Trophic relations in the subarctic North Pacific ecosystem: possible feeding effect from pink salmon. Mar Ecol Prog Ser 150:75-85

Shurin JB, Borer ET, Seabloom EW, Anderson K, Blanchette CA, Broitman B, Cooper SD, Halpern BS (2002) A crossecosystem comparison of the strength of trophic cascades. Ecol Lett 5:785-791

Sieracki ME, Verity PG, Stoecker DK (1993) Plankton community response to sequential silicate and nitrate depletion during the 1989 North Atlantic spring bloom. Deep-Sea Res II 40:213-225

Smith RC, Fraser WR, Stammerjohn SE (2003) Climate variability and ecological response of the marine ecosystem in the western Antarctic Peninsula (WAP) region. In: Greenland D, Goodin DG, Smith RC (eds) Climate variability and ecosystem response at long-term ecological research sites. Oxford University Press, New York, p 158-173

Solan M, Cardinale BJ, Downing AL, Engelhardt KA, Ruesink JL, Srivastava DS (2004) Extinction and ecosystem function in the marine benthos. Science 306:1177-1180

Sommer U (1994) The impact of light intensity and day length on silicate and nitrate competition among marine phytoplankton. Limnol Oceanogr 39:1680-1688

Sotka EE, Thacker RW (2005) Do some corals like it hot? Trends Ecol Evol 20:59-62

Springer AM, Estes JA, van Vliet GB, Williams TM, Doak DF, Danner EM, Forney KA, Pfister B (2003) Sequential megafaunal collapse in the North Pacific Ocean: an ongoing legacy of industrial whaling? Proc Natl Acad Sci USA 100: 12223-12228

Stachowicz JJ, Byrnes JE (2006) Species diversity, invasion success and ecosystem functioning: disentangling the influence of resource competition, facilitation, and extrinsic factors. Mar Ecol Prog Ser 311:251-262 (in this Theme Section)

Stachowicz JJ, Whitlatch RB, Osman RW (1999) Species diversity and invasion resistance in a marine ecosystem. Science 286:1577-1579

Stachowicz JJ, Fried H, Osman RW, Whitlatch RB (2002) Biodiversity, invasion resistance and marine ecosystem function: reconciling pattern and process. Ecology 83: 2575-2590

Steiner CF (2001) The effects of prey heterogeneity and consumer identity on the limitation of trophic-level biomass. Ecology 82:2495-2506

Stibor H, Vadstein O, Diehl S, Gelzleichter A and 10 others

Editorial responsibility: Martin Solan (Guest Editor), Newburgh, UK
(2004) Copepods act as a switch between alternative trophic cascades in marine pelagic food webs. Ecol Lett 7: 321-328

Thébault E, Loreau M (2003) Food-web constraints on biodiversity-ecosystem functioning relationships. Proc Natl Acad Sci USA 100:14949-14954

Tilman D (1996) Biodiversity: population versus ecosystem stability. Ecology 77:350-363

Tilman D (1999) The ecological consequences of changes in biodiversity: a search for general principles. Ecology 80: 1455-1474

Tilman D, Downing JA (1994) Biodiversity and stability in grasslands. Nature 367:363-365

Tilman D, Wedin D, Knops J (1996) Productivity and sustainability influenced by biodiversity in grassland ecosystems. Nature 379:718-720

Tilman D, Lehman C, Thompson K (1997) Plant diversity and ecosystem productivity: theoretical considerations. Proc Natl Acad Sci USA 94:1857-1861

Tilman D, Reich PB, Knops J, Wedin D, Mielke T, Lehman C (2001) Diversity and productivity in a long-term grassland experiment. Science 294:843-845

Venter JC, Remington K, Heidelberg JF, Halpern AL and 19 others (2004) Environmental genome shotgun sequencing of the Sargasso Sea. Science 304:66-74

Verity PG, Smetacek V (1996) Organism life cycles, predation, and the structure of marine pelagic ecosystems. Mar Ecol Prog Ser 130:277-293

Verity PG, Smetacek V, Smayda TJ (2002) Status, trends and the future of the marine pelagic ecosystem. Environ Conserv 29:207-237

Waldbusser, GG, Marinelli RL, Whitlatch RB, Visscher PT (2004) The effects of infaunal biodiversity on biogeochemistry of coastal marine sediments. Limnol Oceanogr 49: $1482-1492$

Wardle DA, Huston MA, Grime JP, Berendse F, Garnier E, Lauenroth WK, Setälä H, Wilson SD (2000) Biodiversity and ecosystem function: an issue in ecology. Bull Ecol Soc Am July 2000:235-239

Worm B, Duffy JE (2003) Biodiversity, productivity, and stability in real food webs. Trends Ecol Evol 18:628-632

Worm B, Sandow M, Oschlies A, Lotze HK, Myers RA (2005) Global patterns of predator diversity in the open oceans. Science 309:1365-1369

Yachi S, Loreau M (1999) Biodiversity and ecosystem productivity in a fluctuating environment: the insurance hypothesis. Proc Natl Acad Sci USA 96:1463-1468

Zehr JP, Waterbury JB, Turner PJ, Montoya JP, Omoregie E, Steward GF, Hansen A, Karl DM (2001) Unicellular cyanobacteria fix $\mathrm{N}_{2}$ in the subtropical North Pacific Ocean. Nature 412:635-638

Submitted: February 8, 2005; Accepted: October 21, 2005 Proofs received from author(s): March 6, 2006 